\title{
Ectopic Hydatidiform Mole a Case Report
}

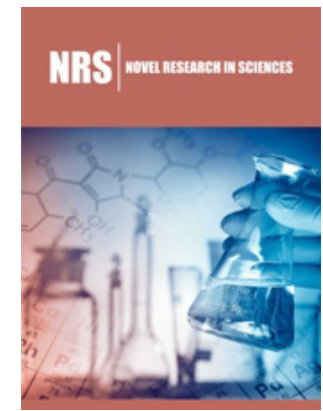

*Corresponding author: Nora Mohamed, Northern Area Armed Forces Hospital, obstetrics and gynecology Department, Saudi Arabia

Orcid ID: https://orcid.org/0000-00028033-1816

Submission: 侮 July 13, 2020

Published: 觜July 31, 2020

Volume 4 - Issue 3

How to cite this article: Nora Mohamed, Laila Moharram, Hedaya Atalla M Alblewi. Ectopic Hydatidiform Mole a Case Report. Nov Res Sci. 4(3). NRS.000586. 2020. DOI: 10.31031/NRS.2020.4.000586

Copyright@ Nora Mohamed, This article is distributed under the terms of the Creative Commons Attribution 4.0 International License, which permits unrestricted use and redistribution provided that the original author and source are credited.

\author{
Nora Mohamed ${ }^{1 *}$, Laila Moharram ${ }^{2}$ and Hedaya Atalla M Alblewi ${ }^{3}$ \\ ${ }^{1}$ Department of obstetrics and gynecology North area armed forces hospital, Saudi Arabia \\ ${ }^{2}$ Department of pathology Salman armed forces hospital, Saudi Arabia \\ ${ }^{3}$ Department of obstetrics and gynecology, Saudi Arabia
}

\section{Abstract}

Background: The incidence of ectopic Hydatidiform mole is presumed to be 1.5 in a million, Making suspicion of the diagnosis less likely. It is important to differentiate between a conventional ectopic and a molar ectopic gestation as they both have the same clinical presentation; however histopathologic features are different. Reaching the proper diagnosis helps in appropriate follow up and counseling.

Case Report: A 32 years old, Gravida 5 para 4, presented to the emergency department with 5 weeks plus 6 days amenorrhea and lower abdominal pain. In view of a high Quantitative beta human chorionic gonadotropin ( $30870 \mathrm{mIU} / \mathrm{L})$, an empty uterus and a complex mass in the left tube $9 \times 8 \mathrm{~mm}$, the patient had laparotomy with left salpingectomy, histopathology of the specimen reported complete mole.

Conclusion: Although rare, molar pregnancy can be extra uterine. Histopathologic confirmation of the final diagnosis, with or without the aid of other tests, is hence advised.

Keywords: Hydatidiform mole; Ectopic pregnancy; Histopathology

\section{Introduction}

Ectopic molar pregnancy is a rare entity with only 40 to 132 reported cases in the literature according to some previous papers [1,2]. We present the first case, to our knowledge, in King Salman Armed Forces hospital. We report this case to highlight the importance of follow up in medical or surgical management of ectopic pregnancy.

\section{Case Report}

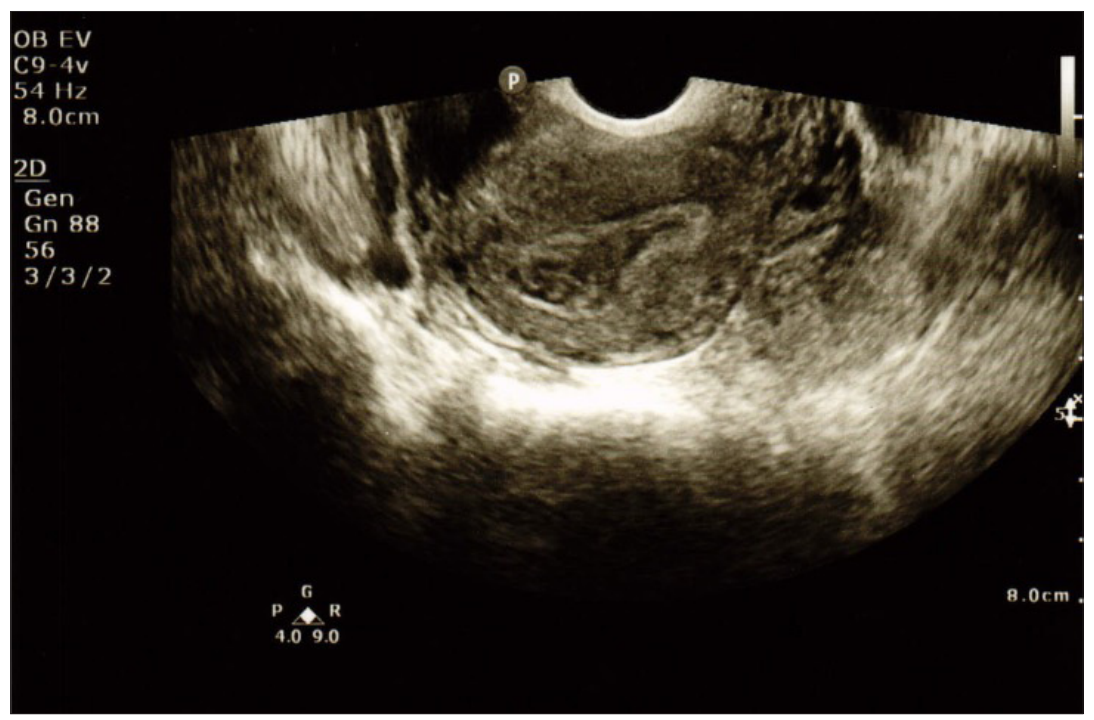

Figure 1: Transvaginal scan, Uterine cavity with blood and blood clots.

A 32 years old, Gravida 5 para 4, previous vaginal deliveries, presented with lower abdominal pain, at 5 weeks plus 6 days from her last menstrual period. on examination, T:36.9 C, BP: 104/63 mmhg, P:78 beat/min, $\mathrm{O}_{2}$ saturation:100\%. Her abdomen was soft, lax and non tender. Quantitative beta human chorionic gonadotropin (BHCG) was $30870 \mathrm{mIU} / \mathrm{L}$, 
ultrasound scan showed endometrial thickness of $1.6 \mathrm{~cm}$, blood and blood clots in the cavity (Figure 1), complex mass in the left tube $9 \times 8 \mathrm{~mm}$, hemorrhagic collection $4.5 \times 2.5 \mathrm{~cm}$ noted along the complex mass (Figure 2) and minimal fluid in the POD. Patient underwent laparotomy, intraoperatively the ampulla of the left tube was dilated, the right tube and both ovaries were normal, around $150 \mathrm{ml}$ of blood was collected in the peritoneal cavity, left salpingectomy was done and the patient was discharged on the second day post op.

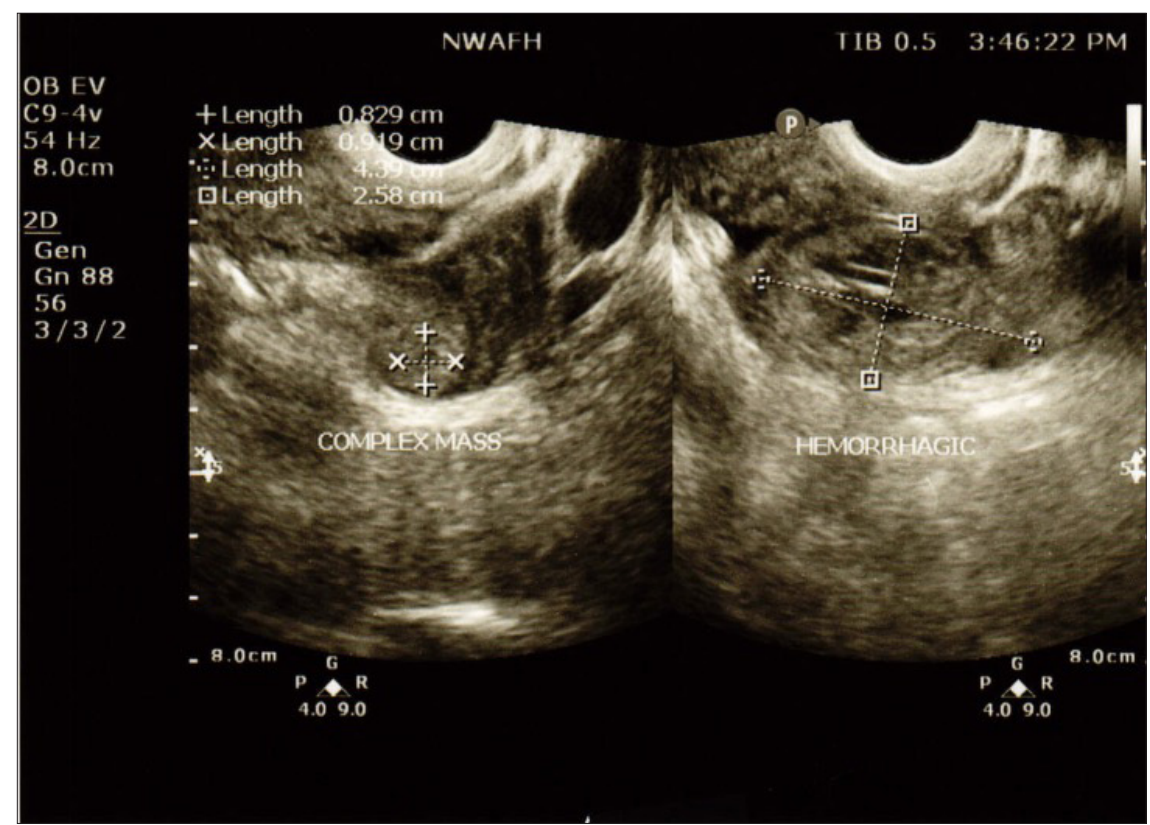

Figure 2: Transvaginal scan, Left complex mass and hemorrhagic collection.

The final diagnosis of histopathology was complete mole. Microscopic examination shows the fallopian tube to be distended by large hydropic villi with circumferential trophoblastic proliferation (Figure 3\&4). The trophoblasts show marked atypia with vacuolation of syncytiotrophoblasts (Figure 5). The villi show occasional cistern formation and apoptotic bodies. No fetal tissue was identified.

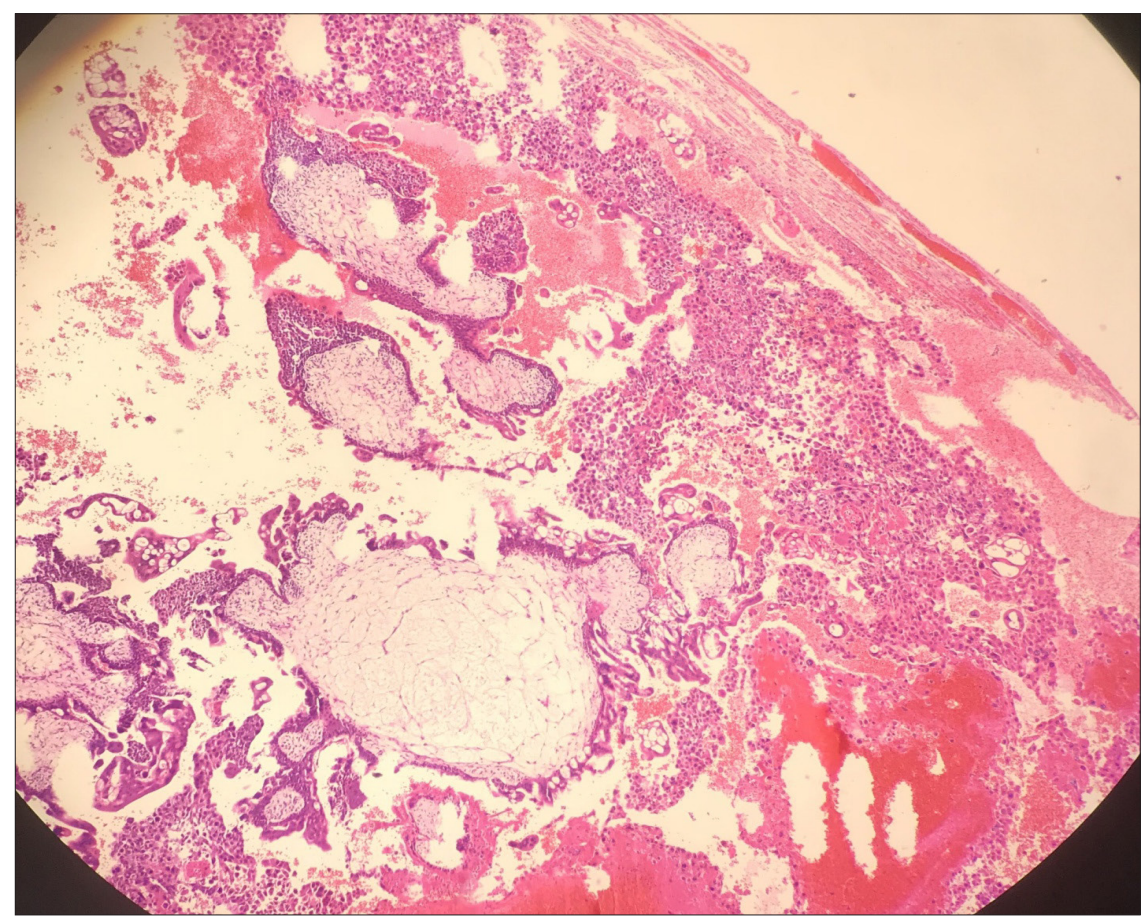

Figure 3: Enlarged villi with circumferential trophoblastic proliferation. 


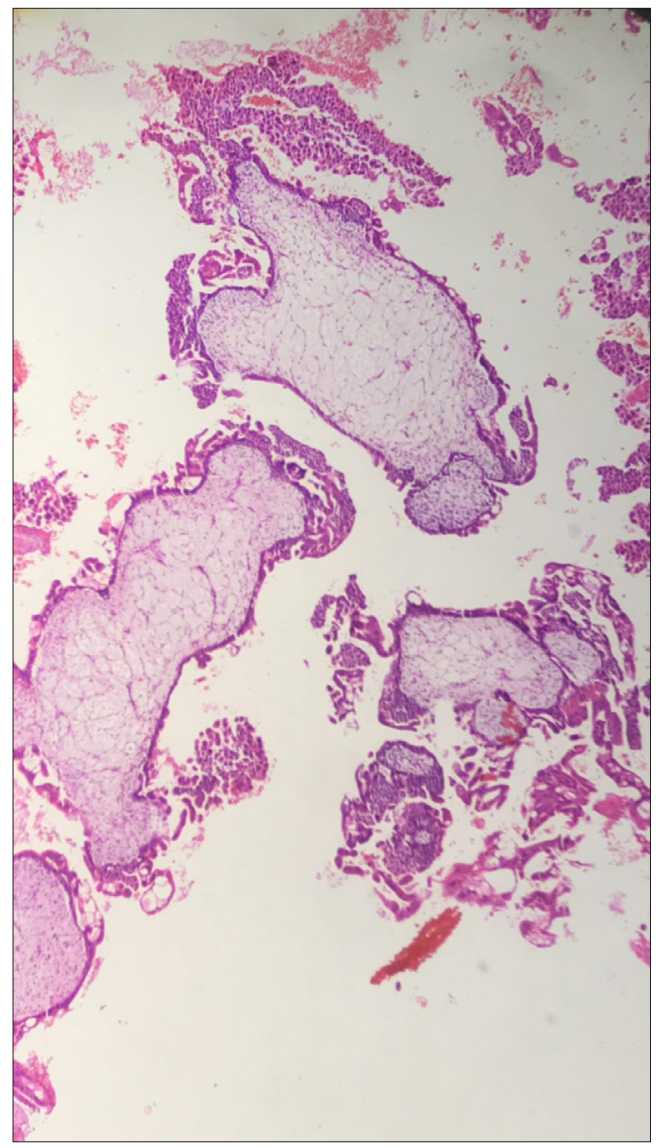

Figure 4: Diffuse villous enlargement with marked hydropic changes.

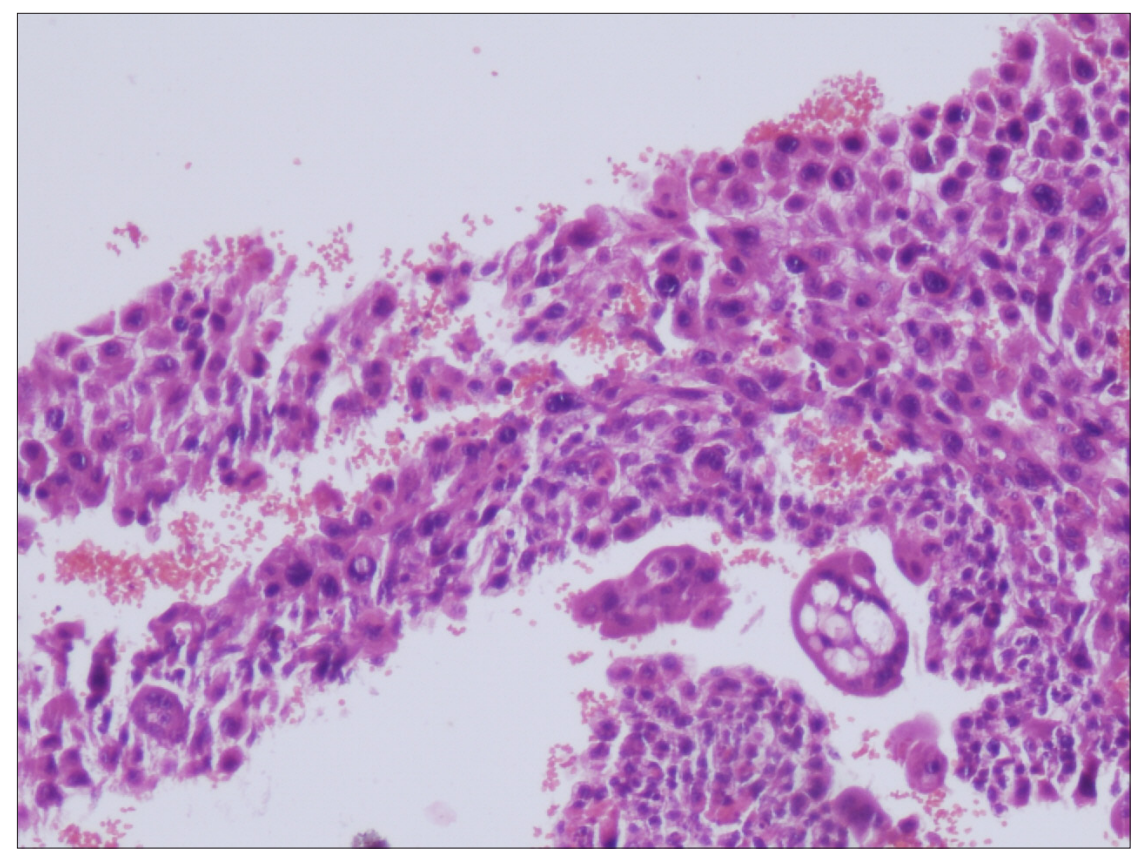

Figure 5: Remarkable cytologic atypia in the trophoblasts. A vacuolated syncitiotrophoblast is also depicted.

The Patient was followed in the outpatient department with serial BHCG. She obtained negative results four weeks from the date of surgery and remained disease free on oral contraceptives.
12 months after her first negative BHCG, she had an uneventful pregnancy, the outcome was comparable to her previous deliveries. 


\section{Discussion}

Ectopic pregnancy accounts for $2 \%$ of all pregnancies as previously studied [3]. It is a fertilized ovum that is implanted outside the endometrial cavity, majority of which are found within the Fallopian tube, whilst the remaining might be found in other sites like the ovary, cervix, cornu and cesarean section scar [4]. Incidence of the genetically abnormal fertilized egg (molar pregnancy) varies greatly in different parts of the world [5]. Ectopic molar pregnancy was reported in the U.K at a rate of 1.5 in a 1000,000 [6]. Clinical symptoms, ultrasound imaging, quantitative BHCG level are salient aspects that aid the diagnosis of molar pregnancy [7]. It is noteworthy that BHCG levels in tubal molar pregnancy mimics that of an ectopic pregnancy, unlike the high values found in an intrauterine molar pregnancy [8]. MRI can provide a valuable tool for diagnosing ectopic hydatidiform moles through features like, intratumoral hypervascularity, molar tissue-like tiny cystic lesions and dense enhancement as cited in a previous study [9].Outcomes post laparoscopic salpingectomy for ectopic molar pregnancy are good, although the risk quantification for persistent disease after surgical removal is difficult due to scarcity of reported cases, In the previously described choriocarcinoma and invasive mole, chemotherapy was the treatment of choice [10]. About 5\% and $15 \%$ of patients who are diagnosed with partial mole and complete mole, respectively, will acquire persistent gestational trophoblastic disease [7]. Proper differentiation between molar ectopic and non molar ectopic is hence mandatory. Patients with ectopic pregnancy who were managed medically and no tissue was available for histopathological evaluation are better followed with BHCG until normal levels are ensured [11].

It is currently presumed that many of the previously reported molar pregnancies are non molar pregnancies [12]. Histological criteria for diagnosing molar pregnancy have been clear in the literature, amongst which are villous enlargement and marked hydropic changes, cistern formation and circumferential trophoblastic proliferation. The diagnosis of ectopic molar pregnancy requires the application of the same diagnostic criteria applicable to their more common uterine counterpart. The pathologic criteria must be strict in the diagnosis of ectopic molars, as some studies have found that there may be an overdiagnosis of ectopic molar pregnancy [1,13]. However, diagnosis can be a challenge to the pathologist since the differences in hydropic abortions and molar pregnancy can be minimal, especially in early miscarriages [14], add to this, evaluation of the specimen depends on the experience of the examiner and might be highly subjective [15]. On the other hand immunohistochemical analysis using antibodies like p57 can distinguish between hydatidiform mole with its different types and hydropic miscarriage [14]. When available, DNA flow cytometric analysis to determine ploidy helps to differentiate between complete mole and partial mole [2]. Reaching the correct diagnosis can decrease the burden on the medical system and the need for further unnecessary follow up. Following a pregnancy affected by hydatidiform mole, whether it is complete or partial mole there is a $2 \%$ risk of recurrence in the next pregnancy, without an increased risk of obstetric complication, compared with the general population [16].

\section{Conclusion}

The clinical presentation of ectopic pregnancy is similar to that of an ectopic molar pregnancy, since the latter has the potential to develop gestational trophoblastic neoplasia it is advised to follow patients diagnosed with ectopic pregnancy by serial quantitative BHCG in Case of unavailability of tissue for histopathology and more advanced studies.

\section{References}

1. Sebire NJ, Lindsay I, Fisher RA, Savage P, Seckl M J (2005) Overdiagnosis of complete and partial hydatidiform mole in tubal ectopic pregnancies. Int J Gynecol Pathol 24: 260-264.

2. Subodhsingh Chauhan, Michael P Diamond, Alan Johns (2003) A case of molar ectopic pregnancy. Asrm 41(4): 1140-1141.

3. Centers for Disease Control and Prevention (CDC) (1995) Ectopic pregnancy: United States, 1990-1992. MMWR Morb Mortal Wkly 44: 46-48.

4. Robert Lee, Carolyn Dupuis, Byron Chen, Andrew Smith, Young H Kim (20018) Diagnosing ectopic pregnancy in the emergency setting. Ultrasonography 37: 78-87.

5. BWL Tham, JE Everard, JA Tidy, D Drew, BW Hancock (2003) Gestational trophoblastic disease in the Asian population of Northern England and North Wales. BJOG: International Journal of Obstetrics and Gynaecology 110: 555-559.

6. AM Gillespie, EA Lidbury, JA Tidy, BW Hancock (2004) The clinical presentation, treatment, and outcome of patients diagnosed with possible ectopic molar gestation. Int J Gynecol Cancer 14: 366-369.

7. Mila TreMentosa Garcia, LaWrence Hsu Lin, Koji Fushida, Rossana Pulcineli Vieira Francisco, Marcelo ZuGaiB (2016) Pregnancy outcomes after chemotherapy for trophoblastic neoplasia. Rev Assoc Med Bras 62(9): 837-842.

8. Najoua Bousfiha, Sanaa Erarhay, Adnane Louba (2012) Ectopic molar pregnancy: a case report. Pan African Medical Journal 11: 63

9. Yasushi Yamada, Satoshi Ohira, Teruyuki Yamazaki and Tanri Shiozawa (2016) Ectopic Molar Pregnancy: Diagnostic Efficacy of Magnetic Resonance Imaging and Review of the Literature. Case Reports in Obstetrics and Gynecology 2016: 7618631.

10. Anthony Richards, Kirsten Black, Selvan Pather (2013) Persistent molar pregnancy in an ectopic tubal pregnancy treated with laparoscopic surgery: A case report. IJCRI 4(4).

11. Fatemeh Davari Tanha, Elham ShirAli, Haleh Rahmanpour, Fediey Haghollahi (2011) Molar Pregnancy Presents as Tubal Ectopic Pregnancy. International Journal of Fertility and Sterility 4(4): 184-186.

12. A Siozos, A Sriemevan (2011) A case of true tubal hydatidiform mole and literature review. BMJ Case Reports 2010: bcr0720092123.

13. Burton JL, Lidbury EA, Gillespie AM (2001) Over-diagnosis of hydatidiform mole in early tubal ectopic pregnancy. Histopathology 38(5): 409-417.

14. Kubelka-Sabit KB, Prodanova I, Jasar D (217) Molecular and immunohistochemical characteristics of complete hydatidiform moles. Bjmg 20(1): 27-34. 
15. J Dianehemming, P Quirke, C Womack, M Wells, C W Elston, C C Bird (1987) Diagnosis of molar pregnancy and persistent trophoblastic disease by flow cytometry. Jclin Pathol 40: 615-620.
16. NJ Sebire, RA Fisher, M Foskett, H Rees, MJ Seckl, ES Newlands (2003) Risk of recurrent hydatidiform mole and subsequent pregnancy outcome following complete or partial hydatidiform molar pregnancy. BJOG: an International Journal of Obstetrics and Gynaecology 110(1): 22-26.

For possible submissions Click below: 